\title{
Association of Upper Lip Coverage with Gingival Inflammation: A Cross-Sectional Study
}

\author{
Manpreet Kaur, Rajinder Kumar Sharma, Shikha Tewari, and Nishi Tanwar
}

\section{ABSTRACT}

Objective: As dryness is reported to be associated with inflammatory conditions in different body parts, incomplete coverage by upper lip may be responsible for gingival inflammation. The objective of the study was to assess status of gingival inflammation with reference to upper lip coverage.

Materials and methods: Patients with plaque-induced gingivitis consisting of 38 individuals with incomplete upper lip coverage (ILC) and 38 individuals with complete upper lip coverage (CLC) were enrolled. Plaque index (PI), gingival index (GI) and bleeding on probing (BOP) were recorded in whole dentition excluding third molars. Bleeding/plaque ratio was also calculated for different regions of dentition. Logistic regression analysis was applied to examine association between BOP at labial sites of maxillary anterior teeth and upper lip coverage.

Results: Significantly higher PI, GI, BOP scores and BOP/plaque ratio were noted at labial sites of maxillary anterior teeth in ILC group as compared to CLC group ( $p=.001, p=.011, p=.004$ and $p=.016$ respectively). Significantly higher scores of BOP were found at labial sites than palatal sites of ILC group ( $p=.003)$. Regression analysis revealed that maxillary anterior labial sites in ILC group were 1.51 times more likely of having BOP (adjusted odds ratio $1.51,95 \%$ confidence interval (CI) 1.13-2.03, $\mathrm{p}=.006$ ).

Conclusion: Incomplete upper lip coverage of maxillary gingiva is associated with higher periodontal inflammatory parameters at labial sites of maxillary anterior teeth.

Keywords: gingiva, gingivitis, inflammation.

\section{INTRODUCTION}

Plaque-induced gingivitis is among the most common diseases of periodontium [1]. Many factors are reported to be contributing either to poor plaque control or to alteration in the host response towards bacterial biofilm, thereby resulting in increased gingival inflammation.

Dryness is reported to be associated with sustained inflammatory conditions in various parts of body viz dry eye disease [2], atopic dermatitis [3], [4], and exercise-induced asthma [5]. As dry conditions are responsible for the inflammatory state in various diseases, such scenario associated with incomplete coverage of maxillary gingiva contributing to increased gingival inflammation in exposed parts of gingiva might exist in oral cavity as well. Lip incompetence has been explored for its association with gingival inflammation in children and adolescents [6]-[9].

Incompetent lips denote inability of lips to form a seal at unstrained rest position of the mandible [10]. Lip seal is presumed to be important for gingival health as various studies reveal lack of lip seal to be associated with gingival inflammation [6], [8], [9] and increased plaque scores [6], [7], [9]. However, lack of association between incompetent estimate this association.

\section{A. Study Design}

Published Online: December 30,2020

ISSN: $2684-4443$

DOI: $10.24018 /$ ejdent.2020.1.6.34

\section{Manpreet Kaur}

Department of Periodontics and Oral Implantology, Post Graduate Institute of Dental Sciences, Rohtak, Haryana, India. (e-mail: manpreetnancy91@ gmail.com) Rajinder Kumar Sharma*

Department of Periodontics and Oral Implantology, Post Graduate Institute of Dental Sciences, Rohtak, Haryana, India. (e-mail: rksharmamds ${ }^{\circledR}$ yahoo.in)

Shikha Tewari

Department of Periodontics and Oral Implantology, Post Graduate Institute of Dental Sciences, Rohtak, Haryana, India. (e-mail:drshikhatewari @ yahoo.com)

Nishi Tanwar

Department of Periodontics and Oral Implantology, Post Graduate Institute of Dental Sciences, Rohtak, Haryana, India. (e-mail: nsh_tanwar@yahoo.co.in)

*Corresponding Author

lip seal and gingivitis in maxillary anterior region has also been reported [11]. Sufficient upper lip coverage of maxillary gingiva in the absence of lip seal might be responsible for this lack of association [11].

A perusal of literature does not reveal any study undertaken to explore association of gingival inflammation with upper lip coverage of maxillary gingiva in adult population. Hence the present study was carried out to

\section{MATERIALS AND METHODS}

This observational cross-sectional study was conducted in the Department of Periodontics and Oral Implantology, Post Graduate Institute of Dental Sciences (PGIDS), Rohtak, Haryana, India. Ethical standards outlined in the Declaration of Helsinki 1975, as revised in 2013, were followed. Ethical Committee PGIDS, Rohtak, Haryana, India approved the study protocol (PGIDS/IEC/2017/08). Patients were recruited after explaining the purpose of the study and obtaining written informed consent. 


\section{B. Study Population}

123 patients were screened from the outpatient Department of Periodontics and Oral Implantology. The study was conducted in 76 patients with plaque induced gingivitis [12] (50 females and 26 males; aged 20 to 35 years; mean age $24.68 \pm 3.70$ years) comprising of 38 individuals with incomplete upper lip coverage (ILC) and 38 individuals with complete upper lip coverage (CLC). Assessment of gingival coverage by upper lip was done with participants in relaxed upright position. The assessment was made with position of the upper lip of the patient at same level as that of the examiner's eye. Individuals with maxillary labial gingiva not covered or incompletely covered by upper lip were included in incomplete upper lip coverage (ILC) group. Complete upper lip coverage (CLC) group comprised of individuals in whom maxillary labial gingiva was covered completely with the upper lip.

\section{Inclusion Criteria}

The inclusion criteria were as follows:

- Systemically healthy individuals with average fullmouth plaque scores within a range of 1.0-2.0.

\section{Exclusion Criteria}

The exclusion criteria were as follows:

- Patients with periodontitis [13], malocclusion, caries, or restorations near gingival margin.

- Patients undergoing orthodontic treatment.

- Patients using drugs known to influence periodontal health for six months before commencement of the study.

- History of periodontal treatment within six months of enrollment in the study.

- Current user or history of tobacco in any form.

- Non-plaque-induced gingival lesions.

- Pregnant women and lactating mothers.

\section{E. Periodontal Examination}

Plaque index (PI) [14], gingival index (GI) [15] were recorded at four sites per tooth and bleeding on probing (BOP) [16] were recorded at six sites per tooth excluding third molars. The sites positive for BOP were calculated as a percentage of total sites positive for the BOP. All clinical parameters were recorded by a single trained, calibrated investigator (MK) to exclude inter-examiner variability. A calibration exercise was performed until reproducibility in $>85 \%$ of measurements done on two occasions 48 hours apart was achieved.

BOP was considered as the primary outcome variable of the study, and PI and GI were secondary outcome variables.

\section{F. Statistical Analysis}

The sample size for the study was calculated using software (G-Power 3.0.10, Heinrich-Heine University Dusseldorf, Dusseldorf, Germany). Based on $85 \%$ power of the study, with $\alpha$ error of 0.05 for two tailed test and allocation ratio of $1: 1,38$ individuals were required in each group with an effect size of 0.7 based on the previous study [17].

Analysis of data was carried out using statistical software (SPSS; v 20, IBM, Chicago, IL). Normality of data was assessed using the Shapiro-Wilk test. As data had non- normal distribution, non parametric statistical tests were applied. Continuous variables such as PI, GI, BOP (\%) and age were expressed as median, interquartile range $\left(\mathrm{Q}_{1}-\mathrm{Q}_{3}\right)$ and mean \pm standard deviation (SD). Intergroup comparison of continuous variables was done employing Mann Whitney $\mathrm{U}$ test. The categorical variables were compared using chi square test between two groups. The association between BOP at labial sites of maxillary anterior teeth and upper lip coverage was assessed by odds ratio (OR) and 95\% confidence intervals $(\mathrm{CI})$, using logistic regression analysis. In the model, the outcome variable included the presence or absence of BOP at labial sites of maxillary anterior teeth, and plaque scores as well as the group to which individuals belong were the categorical predictor variables. Goodness of fit for the regression model was verified by applying the Hosmer-Lemeshow test statistic. Results were considered to be significant at a $\mathrm{p}$ value $<0.05$.

\section{RESUlTS}

Demographic variables and patient characteristics were comparable in both groups ( $\mathrm{p} \geq .05$ ) (Table 1).

TABLE1: DEMOGRAPHIC VARIABLES AND PATIENT CHARACTERISTICS IN THE STUDY POPULATION

\begin{tabular}{|c|c|c|c|c|}
\hline $\begin{array}{c}\text { Demographic } \\
\text { variables and patient } \\
\text { characteristics }\end{array}$ & & $\begin{array}{l}\text { ILC group } \\
\quad(\mathrm{n}=38)\end{array}$ & $\begin{array}{l}\text { CLC group } \\
\quad(n=38)\end{array}$ & $\mathrm{p}$ \\
\hline \multirow[t]{2}{*}{ Age (years) } & $\begin{array}{l}\text { Median } \\
\left(\mathrm{Q}_{1}-\mathrm{Q}_{3}\right)\end{array}$ & $\begin{array}{l}24.00(22.00- \\
27.25)\end{array}$ & $\begin{array}{c}23.50 \\
(21.00- \\
27.00)\end{array}$ & $.311^{\dagger}$ \\
\hline & $\begin{array}{c}\text { Mean } \pm \\
\text { SD }\end{array}$ & $25.08 \pm 3.72$ & $\begin{array}{c}24.29 \pm \\
3.70\end{array}$ & \\
\hline Female:Male & & $27: 11$ & $23: 15$ & $.333 *$ \\
\hline $\begin{array}{l}\text { Brushing twice or } \\
\text { more in a day }\end{array}$ & & 16 & 24 & $.066^{*}$ \\
\hline Use of interdental aids & & 7 & 11 & $.280 *$ \\
\hline $\begin{array}{l}\text { Education above } \\
\text { matriculation }\end{array}$ & & 35 & 33 & $.455^{*}$ \\
\hline
\end{tabular}

No significant difference was found on intergroup comparison of whole dentition PI, GI, and BOP ( $\mathrm{p} \geq .05)$ (Table 2). Maxillary anterior teeth had significantly higher PI, GI, and BOP in ILC group than in CLC group ( $\mathrm{p}=.002$; $\mathrm{p}=.006 ; \mathrm{p}=.006$ respectively) (Table 2 ).

In mandibular anterior teeth, higher scores of all parameters were found in ILC group than CLC group but differences were insignificant $(\mathrm{p} \geq .05)$ (Table 2). However, similar findings were observed in maxillary posterior as well as mandibular posterior teeth of both groups ( $\mathrm{p} \geq .05$ ) (Table 2).

Intergroup comparison of parameters on labial and palatal sites of maxillary anterior teeth revealed significantly higher PI, GI, and BOP at labial sites in ILC group than in CLC group ( $\mathrm{p}=.001 ; \mathrm{p}=.011 ; \mathrm{p}=.004)$ (Table 3). Significantly higher PI was also noticed at palatal sites of maxillary anterior teeth in ILC group $(\mathrm{p}=.043)$ with no significant difference in other parameters of this region in both the groups ( $\mathrm{p} \geq .05)$ (Table 3). Labial and lingual sites of mandibular anterior teeth also exhibited insignificant intergroup difference in all parameters ( $\mathrm{p} \geq .05)$ (Table 3 ).

When parameters were compared between labial and palatal sites of maxillary anterior teeth in ILC group, similar 
PI $(\mathrm{p}=.879)$ but significantly higher BOP was found at labial sites $(p=.003)$ (Table 3). In mandibular anterior teeth, significantly higher GI was noticed at lingual sites as compared to labial sites in this group $(\mathrm{p}=.020)$ (Table 3$)$.

In CLC group, no significant difference was found in PI, GI, and BOP on comparing parameters between labial and palatal surfaces of maxillary anterior teeth ( $\mathrm{p} \geq .05)$ (Table 3$)$. In mandibular anterior teeth, lingual PI was significantly higher than labial PI in CLC group $(\mathrm{p}=.021)$ with no significant difference in other parameters $(\mathrm{p} \geq .05)$ (Table 3$)$.
Bleeding/plaque ratio was significantly higher at labial sites of maxillary anterior teeth in ILC group than CLC group ( $\mathrm{p}=.016)$ as shown in Table 4 . There was no statistical difference in bleeding/plaque ratio in other regions of dentition ( $\mathrm{p} \geq .05$ ) (Table 4).

After adjusting for plaque levels, presence of BOP at labial sites of maxillary anterior teeth was significantly associated with ILC (OR 1.51, 95\% CI 1.13-2.03; p=.006) (Table 5).

TABLE 2: DESCRIPTIVE STATISTICS OF CLINICAL PARAMETERS IN DIFFERENT REGIONS OF MOUTH IN ILC AND CLC GROUP

\begin{tabular}{|c|c|c|c|c|c|c|c|c|c|c|}
\hline \multirow{2}{*}{ Region } & & \multicolumn{3}{|c|}{ PI } & \multicolumn{3}{|c|}{ GI } & \multicolumn{3}{|c|}{ BOP } \\
\hline & & ILC group & CLC group & $\mathrm{p}^{*}$ & ILC group & CLC group & $\mathrm{P} *$ & ILC group & CLC group & $\mathrm{p}^{*}$ \\
\hline $\begin{array}{c}\text { Whole } \\
\text { dentition }\end{array}$ & $\operatorname{Median}\left(\mathrm{Q}_{1}-\mathrm{Q}_{3}\right)$ & $\begin{array}{c}1.37(1.15- \\
1.48)\end{array}$ & $\begin{array}{c}1.22(1.13- \\
1.41)\end{array}$ & .192 & $\begin{array}{c}1.18(1.11- \\
1.29)\end{array}$ & $\begin{array}{c}1.15(1.08- \\
1.24)\end{array}$ & .429 & $\begin{array}{l}25.60(11.90- \\
35.86)\end{array}$ & $\begin{array}{c}20.83(11.90- \\
31.08)\end{array}$ & .607 \\
\hline \multirow{2}{*}{$\begin{array}{l}\text { Maxillary } \\
\text { anterior } \\
\text { teeth }\end{array}$} & $\operatorname{Median}\left(\mathrm{Q}_{1}-\mathrm{Q}_{3}\right)$ & $\begin{array}{c}1.29(1.08- \\
1.58)\end{array}$ & $\begin{array}{c}1.08(1.03- \\
1.21)\end{array}$ & .002 & $\begin{array}{c}1.17(1.08- \\
1.34)\end{array}$ & $\begin{array}{c}1.04(1.00- \\
1.18)\end{array}$ & .006 & $\begin{array}{c}18.06(8.33- \\
44.44)\end{array}$ & $\begin{array}{c}8.33(2.78- \\
19.44)\end{array}$ & .006 \\
\hline & Mean \pm SD & $1.37 \pm .32$ & $1.16 \pm .19$ & & $1.22 \pm .20$ & $1.10 \pm .13$ & & $25.37 \pm 20.21$ & $13.98 \pm 15.03$ & \\
\hline \multirow{2}{*}{$\begin{array}{c}\text { Mandibula } \\
\text { r anterior } \\
\text { teeth }\end{array}$} & $\operatorname{Median}\left(\mathrm{Q}_{1}-\mathrm{Q}_{3}\right)$ & $\begin{array}{c}1.44(1.08- \\
1.75)\end{array}$ & $\begin{array}{c}1.23(1.07- \\
1.56)\end{array}$ & .265 & $\begin{array}{c}1.21(1.13- \\
1.38)\end{array}$ & $\begin{array}{c}1.08(1.04- \\
1.34)\end{array}$ & .081 & $\begin{array}{c}25.00(10.42- \\
39.59)\end{array}$ & $\begin{array}{c}13.89(4.87- \\
40.28)\end{array}$ & .223 \\
\hline & Mean \pm SD & $1.46 \pm .38$ & $1.36 \pm .38$ & & $1.24 \pm .18$ & $1.22 \pm .26$ & & $27.47 \pm 19.65$ & $24.93 \pm 26.41$ & \\
\hline \multirow{2}{*}{$\begin{array}{l}\text { Maxillary } \\
\text { posterior } \\
\text { teeth }\end{array}$} & $\operatorname{Median}\left(\mathrm{Q}_{1}-\mathrm{Q}_{3}\right)$ & $\begin{array}{c}1.33(1.13- \\
1.49)\end{array}$ & $\begin{array}{c}1.25(1.09- \\
1.44)\end{array}$ & .270 & $\begin{array}{c}1.18(1.08- \\
1.28)\end{array}$ & $\begin{array}{c}1.19(1.09- \\
1.28)\end{array}$ & .888 & $\begin{array}{c}25.00(10.42- \\
34.89)\end{array}$ & $\begin{array}{c}26.64(18.23- \\
32.29)\end{array}$ & .286 \\
\hline & Mean \pm SD & $1.35 \pm .25$ & $1.31 \pm .28$ & & $1.19 \pm .14$ & $1.21 \pm .17$ & & $24.34 \pm 15.20$ & $27.66 \pm 13.11$ & \\
\hline \multirow{2}{*}{$\begin{array}{c}\text { Mandibula } \\
\text { r posterior } \\
\text { teeth }\end{array}$} & $\operatorname{Median}\left(\mathrm{Q}_{1}-\mathrm{Q}_{3}\right)$ & $\begin{array}{c}1.24(1.15- \\
1.40)\end{array}$ & $\begin{array}{c}1.25(1.18- \\
1.42)\end{array}$ & .269 & $\begin{array}{c}1.16(1.09- \\
1.20)\end{array}$ & $\begin{array}{c}1.16(1.13- \\
1.28)\end{array}$ & .111 & $\begin{array}{c}21.88(11.98- \\
31.25)\end{array}$ & $\begin{array}{c}29.17(14.06- \\
37.50)\end{array}$ & .250 \\
\hline & Mean \pm SD & $1.28 \pm .21$ & $1.33 \pm .23$ & & $1.16 \pm .11$ & $1.20 \pm .12$ & & $23.12 \pm 14.75$ & $26.81 \pm 14.64$ & \\
\hline
\end{tabular}

* Comparison between groups made using Mann Whitney U test.Statistically significant $\mathrm{p}$ values are indicated in bold and italics.

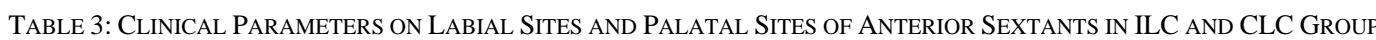

\begin{tabular}{|c|c|c|c|c|c|c|c|c|c|c|c|}
\hline \multirow[b]{2}{*}{ Region } & \multirow[b]{2}{*}{ Sites } & & \multicolumn{3}{|c|}{ PI } & \multicolumn{3}{|c|}{ GI } & \multicolumn{3}{|c|}{ BOP } \\
\hline & & & $\begin{array}{l}\text { ILC } \\
\text { group }\end{array}$ & $\begin{array}{l}\text { CLC } \\
\text { group }\end{array}$ & $\mathrm{p}^{*}$ & $\begin{array}{l}\text { ILC } \\
\text { group }\end{array}$ & $\begin{array}{l}\text { CLC } \\
\text { group }\end{array}$ & $\mathrm{p}^{*}$ & $\begin{array}{l}\text { ILC } \\
\text { group }\end{array}$ & $\begin{array}{l}\text { CLC } \\
\text { group }\end{array}$ & $\mathrm{p}^{*}$ \\
\hline \multirow{5}{*}{$\begin{array}{c}\text { Maxillary } \\
\text { anterior teeth }\end{array}$} & \multirow[t]{2}{*}{ Labial } & $\operatorname{Median}\left(Q_{1}-Q_{3}\right)$ & $\begin{array}{c}1.17(1.06 \\
-1.57)\end{array}$ & $\begin{array}{c}1.06(1.00 \\
-1.17)\end{array}$ & $\begin{array}{c}.00 \\
1\end{array}$ & $\begin{array}{c}1.17(1.06 \\
-1.33)\end{array}$ & $\begin{array}{c}1.07(1.00 \\
-1.13)\end{array}$ & .011 & $\begin{array}{c}30.56(11.11- \\
55.56)\end{array}$ & $\begin{array}{c}\text { 11.11(.00- } \\
23.61)\end{array}$ & \multirow[t]{2}{*}{.004} \\
\hline & & Mean \pm SD & $1.35 \pm .37$ & $1.13 \pm .21$ & & $1.22 \pm .22$ & $1.11 \pm .13$ & & $33.31 \pm 25.09$ & $17.68 \pm 20.51$ & \\
\hline & \multirow[t]{2}{*}{ Palatal } & $\operatorname{Median}\left(\mathrm{Q}_{1}-\mathrm{Q}_{3}\right)$ & $\begin{array}{c}1.33(1.00 \\
-1.67)\end{array}$ & $\begin{array}{c}1.09(1.00 \\
-1.43)\end{array}$ & $\begin{array}{c}.04 \\
3\end{array}$ & $\begin{array}{c}1.17(1.00 \\
-1.37)\end{array}$ & $\begin{array}{c}1.00(1.00 \\
-1.17)\end{array}$ & .097 & $\begin{array}{c}11.11(.00- \\
25.00)\end{array}$ & $\begin{array}{c}5.56(.00- \\
18.06)\end{array}$ & \multirow[t]{3}{*}{.083} \\
\hline & & Mean \pm SD & $1.41 \pm .41$ & $1.22 \pm .28$ & & $1.22 \pm .28$ & $1.13 \pm .21$ & & $17.43 \pm 19.66$ & $10.15 \pm 13.30$ & \\
\hline & $\mathrm{p}^{\dagger}$ & & .879 & .482 & & .357 & .188 & & .003 & .062 & \\
\hline \multirow{5}{*}{$\begin{array}{l}\text { Mandibular } \\
\text { anterior teeth }\end{array}$} & Labial & $\operatorname{Median}\left(\mathrm{Q}_{1}-\mathrm{Q}_{3}\right)$ & $\begin{array}{c}1.36(1.06 \\
-1.67)\end{array}$ & $\begin{array}{c}1.11(1.00 \\
-1.52)\end{array}$ & $\begin{array}{c}.13 \\
4\end{array}$ & $\begin{array}{c}1.22(1.06 \\
-1.33)\end{array}$ & $\begin{array}{c}1.06(1.00 \\
-1.29)\end{array}$ & .183 & $\begin{array}{c}27.78(9.72- \\
38.89)\end{array}$ & $\begin{array}{c}5.56(.00- \\
44.44)\end{array}$ & \multirow[t]{2}{*}{.149} \\
\hline & \multirow{3}{*}{ Lingual } & Mean \pm SD & $1.41 \pm .40$ & $1.29 \pm .39$ & & $1.20 \pm .18$ & $1.19 \pm .26$ & & $25.94 \pm 20.35$ & $24.24 \pm 31.25$ & \\
\hline & & $\operatorname{Median}\left(\mathrm{Q}_{1}-\mathrm{Q}_{3}\right)$ & $\begin{array}{c}1.59(1.13 \\
-2.00)\end{array}$ & $\begin{array}{c}1.50(1.00 \\
-2.00)\end{array}$ & $\begin{array}{c}.77 \\
6\end{array}$ & $\begin{array}{c}1.33(1.17 \\
-1.67)\end{array}$ & $\begin{array}{c}1.17(1.00 \\
-1.37)\end{array}$ & .148 & $\begin{array}{c}27.78(5.56- \\
47.22)\end{array}$ & $\begin{array}{c}19.45(5.56- \\
44.44)\end{array}$ & \multirow[t]{3}{*}{.496} \\
\hline & & Mean \pm SD & $1.61 \pm .53$ & $1.56 \pm .50$ & & $1.37 \pm .31$ & $1.29 \pm .31$ & & $29.01 \pm 23.57$ & $25.61 \pm 25.08$ & \\
\hline & $\mathrm{p}^{\dagger}$ & & .106 & .021 & & .020 & .111 & & .635 & .234 & \\
\hline
\end{tabular}

${ }^{\dagger}$ Mann- Whitney U test for comparison between labial and palatal/lingual sites within group. *Mann- Whitney U test for comparison between two groups. Statistically significant $\mathrm{p}$ values are indicated in bold and italics.

TABLE 4: BLEEDING/ PlaQUE RATIO IN DIFFERENT REGIONS OF DENTITION

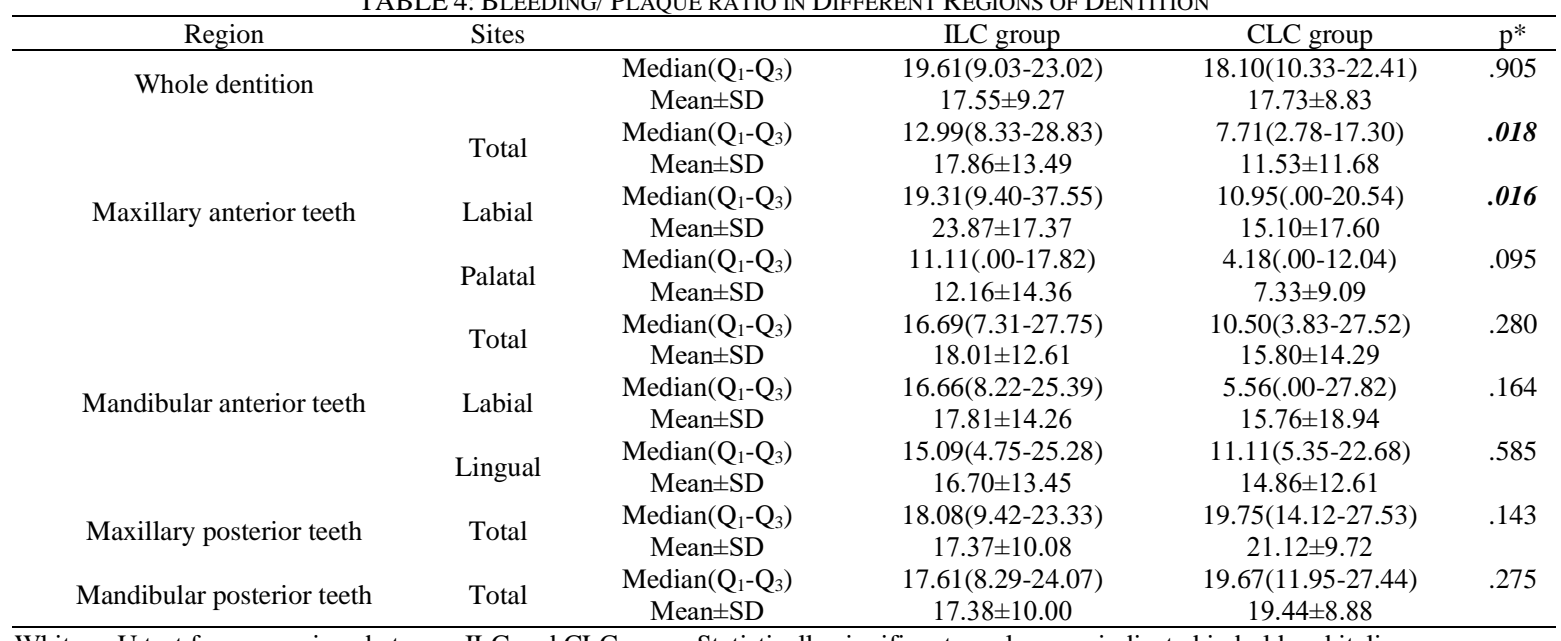

* Mann- Whitney U test for comparison between ILC and CLC group.Statistically significant $\mathrm{p}$ values are indicated in bold and italics. 
TABLE 5: LOGISTIC REGRESSION ANALYSES OF THE ASSOCIATION BETWEEN THE PRESENCE OF BOP AT MAXILLARY ANTERIOR LABIAL SiteS AND UPPER LIP COVERAGE

\begin{tabular}{|c|c|c|c|c|}
\hline Model & & OR & $95 \% \mathrm{CI}$ & $\mathrm{p}$ \\
\hline \multirow[t]{2}{*}{ BOP } & Unadjusted & 2.41 & $1.87-3.11$ & .000 \\
\hline & Adjusted $^{\dagger}$ & 1.51 & $1.13-2.03$ & .006 \\
\hline
\end{tabular}

Statistically significant $\mathrm{p}$ values are indicated in bold and italics.

${ }^{\dagger}$ Adjusted for plaque.

\section{DISCUSSION}

To the best of our knowledge, this is the first crosssectional study evaluating the association of decreased upper lip coverage with gingival inflammation in different regions of dentition in adult population. None of the periodontal parameters in whole dentition exhibited a significant difference between ILC and CLC group. Stringent inclusion and exclusion criteria particularly the inclusion of patients with narrow range of PI might be accountable for similar plaque scores, and hence comparable whole dentition periodontal inflammatory status in participants of both groups.

As compared to CLC group, ILC group demonstrated significantly higher plaque scores and gingival inflammation at labial sites of maxillary anterior teeth. These results are in accordance with results of previous study by Wagaiyu and Ashley [9] in children and adolescents that revealed a significant increase in the number of sites with plaque and BOP scores with respect to maxillary incisors as upper lip coverage decreased. Addy et al [17] also reported significantly increased PI and BOP at labial sites of maxillary anterior teeth with diminishing upper lip coverage in adolescents.

The exact mechanism responsible for increased gingival scores in maxillary anterior teeth of individuals with decreased upper lip coverage is not known. Increase in plaque levels due to reduced frictional cleansing action of upper lip might be an important factor responsible for aggravated inflammation of periodontal tissues [17]. Minimal thickness of the salivary film in the maxillary labial region [18] might have further diminished the salivary defense mechanism on the gingiva. In the present study, the results of logistic regression analysis revealed that chances of having BOP at labial sites of maxillary anterior teeth were 1.51 times more in ILC group as compared to CLC group after controlling for plaque. Increased gingival inflammation in absence of higher plaque [19] further substantiates this assumption. Previous studies emphasized the role of oral dryness in oral inflammation [20], [21]. In the oral cavity, salivary mucins bind with water to form coating over oral mucosa thereby protecting tissues from desiccation [22]. In individuals with xerostomia, increased plaque scores and gingival inflammation are reported [23]. In mouth breathers, edematous and enlarged gingiva is reported in maxillary anterior region which is suspected to be consequence of drying [21]. However, in rodents, no inflammation and edema are seen on air drying the oral mucous membrane [24].

Resolution of periodontal inflammation after scaling and root planning is affected in mouth breathers [25] which may be attributed to dryness and alteration in hydration of periodontal tissues. There is evidence regarding contribution of dryness in various inflammatory conditions viz exercise- induced asthma [5], dry eye disease [2], and atopic dermatitis [3], [4]. Exercise-induced asthma occurs due to water loss from upper airways during humidification of cold, dry air [5]. In dry eye disease, instability, or hyperosmolarity of tear film [26] occurs due to either its increased evaporation or decreased formation [27]. Use of artificial tear drops and ocular lubricants improves this condition by returning an epithelial condition to a more normal state. Likewise, application of emollients on the skin is found to be beneficial in individuals with dry skin associated increased susceptibility to develop atopic dermatitis [3], [4].

Gingivitis is a precursor for periodontitis and eventual tooth loss [28]. Increased bleeding scores at labial sites of maxillary anterior teeth of ILC group (33\% versus 18\%) may indicate increased probability for periodontal tissue destruction at these sites. However, positive predictive value of BOP is never ascertained to be more than 30\% [29].

Previous study by van der Velden U et al [30] revealed that individuals with aggressive periodontitis have higher bleeding/plaque ratio as compared to individuals with healthy periodontal tissues at sites with shallow probing depths. It is therefore hypothesized that an increased periodontal breakdown may be the result of an exaggerated inflammatory response of the host (in terms of BOP) to the amount of plaque. Furthermore, role of bleeding/plaque ratio as an indicator of periodontal destruction is recommended [30]. In the present study, significantly higher bleeding/plaque ratio at labial sites of maxillary anterior teeth in ILC group implied an exaggerated inflammatory response and hence increased likelihood for the emergence of periodontitis at these sites.

In the present study, although clinical parameters in maxillary anterior palatal sites were higher in ILC group, difference was statistically significant only for PI scores. Palatal BOP scores in CLC group (10.29\%) versus ILC group $(17.43 \%)$ implied to be clinically significant. However, Addy et al [17] reported increased palatal bleeding sites without corresponding increase in plaque as degree of lip coverage decreased. The hard palate is the least wet mucosal site due to thin layer of salivary coating [18]. Dryness in this region might have contributed to increased accumulation of plaque or might itself caused inflammation of the gingiva.

In this study, significantly higher BOP at labial sites of maxillary anterior teeth $(33.30 \%)$ as compared to palatal sites $(17.43 \%)$ in ILC group is in accordance with a study by Wagaiyu and Ashley [9]. In the present study, no significant difference in plaque scores was found between labial and palatal sites of maxillary anterior teeth in ILC group. This pattern of significantly higher BOP regardless of comparable plaque score in maxillary labial versus palatal sites was not observed in CLC group. This represents that besides plaque, the contribution of other mechanisms such as drying of the oral mucosa, reduced local defense mechanisms related to salivary constituents [19], and local ecological alterations modifying the microbiological composition of plaque [19] in higher inflammation of labial gingiva of ILC group cannot be precluded.

In mandibular anterior region, all parameters exhibited insignificant differences between two groups. This may be 
consequence of gingival coverage by lower lip, hence decreased upper lip coverage had little effect in the mandibular anterior region. Wagaiyu and Ashley [9] observed association of decreased upper lip coverage restricted mostly to maxillary anterior teeth. However, Addy et al [17] found significant increase in plaque and BOP in mandibular anterior teeth as upper lip coverage decreased.

Intergroup comparison of PI, GI, and BOP on maxillary posterior and mandibular posterior teeth revealed no significant differences. Protection of gingiva by cheeks and saliva in these areas may be accountable for identical periodontal inflammatory status and plaque levels in both groups.

This study has a merit over previous studies as the association of upper lip coverage with gingival inflammation was assessed in all regions of dentition in the adult population.

As cross-sectional studies reveal only association, longitudinal studies need to be accomplished to evaluate impact of decreased lip coverage on the periodontal inflammatory status with inclusion of the microbiological analysis of plaque and inflammatory markers.

\section{CONCLUSIONS}

Within the limits of the study, an association between decreased upper lip coverage and increased gingival inflammation and plaque scores on labial sites of maxillary anterior teeth is demonstrated. This increase in gingival inflammation if left untreated, may predispose individuals to periodontal tissue breakdown. Therefore, strategies need to be explored and adopted for the management of gingival inflammation at labial sites of maxillary anterior teeth in individuals with decreased upper lip coverage.

\section{REFERENCES}

[1] Page RC. Oral health status in the United States: Prevalence of inflammatory periodontal diseases. J Dent Educ. 1985; 49(6):354367.

[2] Stevenson W, Chauhan SK, Dana R. Dry eye disease. An immunemediated ocular surface disorder.Arch Ophthalmol. 2012;130(1):90100.

[3] Lio PA. Efficacy of a moisturizing foam in skin barrier regeneration and itch relief in subjects prone to atopic dermatitis. J Drugs Dermatol. 2016;15(11): s77-s80.

[4] Schario M, Lunnemann L, Stroux A, Reisshauer A, Zuberbier T, Blume-Peytavi U, et al.Children with dry skin and atopic predisposition: daily use of emollients in a participant-blinded, randomized, prospective trial. Skin Pharmacol Physiol. 2014;27(4):208-216.

[5] Anderson SD, Holzer K. Exercise-induced asthma: is it the right diagnosis in elite athletes? J Allergy Clin Immunol. 2000;106(3):419428.

[6] Gulati MS, Grewal N, Kaur A. A comparative study of effects of mouth breathing and normal breathing on gingival health in children. J Indian Soc PedodPrev Dent. 1998;16(3):72-83.

[7] Kolawole KA, Otuyemi OD, Oziegbe EO. The relationship between malocclusion, lip competence and gingival health in a group of schoolchildren.Rev ClínPesqOdontol. 2010;6(3):239-247.

[8] Sutcliffe P. Chronic anterior gingivitis. An epidemiological study in schoolchildren. Br Dent J. 1968;125(2):47-55.

[9] Wagaiyu EG and Ashley FP. Mouthbreathing, lip seal and upper lip coverage and their relationship with gingival inflammation in 11-14 year old schoolchildren. J Clin Periodontol. 1991;18(9):698-702.

[10] Naini FB. Lip seals. Letters to editor. Br Dent J. 2010;209(3):106.

[11] Geiger AM, Wasserman BH, Turgeon LR. Relationship of Occlusion and Periodontal Disease Part VI.- Relation of Anterior Overjet and
Overbite to Periodontal Destruction and Gingival Inflammation. J Periodontol. 1973;44(3):150-157.

[12] Armitage GC. Development of a Classification Systemfor Periodontal Diseases and Conditions. Ann Periodontol. 1999;4(1):16.

[13] Eke PI, Page RC, Wei L, Thornton-Evans G, Genco RJ. Update of the Case Definitionsfor Population-Based Surveillanceof Periodontitis. J Periodontol. 2012;83(12): 1449-1454.

[14] Silness J, Loe H. Periodontal disease in pregnancy.II. Correlation between oral hygieneand periodontal condition. Acta Odontol Scand. 1964;22(1):121-135.

[15] Loe H, Silness J. Periodontal disease in pregnancy. I. Prevalence and severity.Acta Odontol Scand. 1963;21(6):533-551.

[16] Lang NP, Adler R, Joss A, Nyman S. Absence of bleeding on probing. An indicator of periodontal stability.J Clin Periodontol. 1990;17(10):714-721.

[17] Addy M, Dummer PMH, Hunter ML, Kingdom A, Shaw WC. A study of the association of fraenal attachment, lip coverage and vestibular depth with plaque and gingivitis. $J$ Periodontol. 1987;58(11):752-757.

[18] DiSabato-Mordarski T, Kleinberg I. Measurement and comparison of the residual saliva on various oral mucosal and dentition surfaces in humans. Arch Oral Biol. 1996;41(7):655-665.

[19] Jacobson L. Mouthbreathing and gingivitis. 1. Gingival conditions in children with epipharyngeal adenoids. $J$ Periodontal Res. 1973;8(5):269-277.

[20] Bhatia A, Sharma RK, Tewari S, Narula SC. A randomized clinical trial of salivary substitute as an adjunct to scaling and root planing for management of periodontal inflammation in mouth breathing patients.J Oral Sci. 2015;57(3):241-247.

[21] Lite T, DiMaio DJ, Burman LR. Gingival pathosis in mouth breathers: A clinical and histopathologic study and a method of treatment. Oral Surg Oral Med Oral Pathol. 1955;8(4):382-391.

[22] Mandel ID. The functions of saliva.J Dent Res. 1987;66(Spec Iss):623-627.

[23] Mizutani S, Ekuni D, Tomofuji T, Azuma T, Kataoka K, Yamane $\mathrm{M}$, et al. Relationship between xerostomia and gingival condition in young adults. J Periodontal Res. 2015;50(1):74-79.

[24] Klingsberg J, Cancellaro LA, Butcher EO. Effects of Air Drying on Rodent Oral Mucous Membrane: A Histologic Study of Simulated Mouth Breathing. J Periodontol. 1961;32(1):38-42.

[25] Kaur M, Sharma RK, Tewari S, Narula SC. Influence of mouth breathing on outcome of scaling and root planing in chronic periodontitis. BDJ Open. 2018 Nov 9;4:17039. doi: 10.1038/s41405018-0007-3.

[26] International Dry Eye Workshop (DEWS). The definition and classification of dry eye disease: report of the Definition and Classification Subcommittee of the International Dry Eye Workshop. Ocul Surface.2007;5(2):75-92.

[27] Lemp MA. Report of the National Eye Institute/industry Workshop on clinical trials in dry eye. CLAO J. 1995;21(4):221-232.

[28] Schätzle M, Löe H, Lang NP, Bürgin W, Anerud A, Boysen H. The clinical course of chronic periodontitis. J Clin Periodontol. 2004;31(12):1122-1127.

[29] Lang NP, Joss A, Orsanic T, Gusberti FA, Siegrist BE. Bleeding on probing. A predictor for the progression of periodontal disease? $J$ Clin Periodontol. 1986;13(6):590-596.

[30] van der Velden U, Winkel EG, Abbas F. Bleeding/plaque ratio. A possible prognostic indicator for periodontal breakdown. J Clin Periodontol. 1985;12(10):861-866. 